\section{Case Reports in Neurology}

Case Rep Neurol 2020;12:212-217

DOI: 10.1159/000508588

Published online: December 14, 2020
(C) 2020 The Author(s)

Published by S. Karger AG, Basel www.karger.com/crn

This article is licensed under the Creative Commons Attribution-NonCommercial 4.0 International License (CC BY-NC) (http://www.karger.com/Services/OpenAccessLicense). Usage and distribution for commercial purposes requires written permission.

\title{
NeuroAid II (MLC901) in Haemorrhagic Stroke
}

\author{
Chai-Hoon Nowel Tan ${ }^{a}$ David Choy ${ }^{b}$ \\ Narayanaswamy Venketasubramanian ${ }^{b}$ \\ aYong Loo Lin School of Medicine, National University of Singapore, \\ Singapore, Singapore; ${ }^{b}$ Raffles Neuroscience Centre, Raffles Hospital, \\ Singapore, Singapore
}

\section{Keywords}

Haemorrhagic stroke $\cdot$ NeuroAid II $\cdot$ MLC901 $\cdot$ Stroke recovery

\begin{abstract}
Stroke is a leading cause of death and disability. NeuroAid (MLC601), which originates from Traditional Chinese Medicine, comprises herbal and animal components, and has been shown to improve the functional status of patients after ischaemic stroke. The use of NeuroAid II (MLC901), which comprises only the herbal components of MLC601, in haemorrhagic stroke has not been previously reported. Our patient is a 63-year-old male with a significant stroke risk factor of hypertension. He developed visual field defect, aphasia, unilateral weakness, and hemisensory loss. CT scan showed a left thalamic haemorrhage. In addition to anti-hypertensive therapy and intensive rehabilitation, he was prescribed MLC901. Over a period of 6 months, he had significant improvements in his motor, sensory, and speech function. There were no adverse events, serial brain CT scans showed resolution of the haemorrhage. MLC901 may have a role in post-stroke recovery after intracranial haemorrhage.
\end{abstract}




\section{Case Reports in Neurology}

Case Rep Neurol 2020;12:212-217

\begin{tabular}{l|l}
\hline DOI: $10.1159 / 000508588$ & (c) 2020 The Author(s). Published by S. Karger AG, Basel
\end{tabular} www.karger.com/crn

Tan et al.: NeuroAid II (MLC901) in Haemorrhagic Stroke

\section{Introduction}

Globally, the absolute number of individuals with stroke, stroke-related deaths, and overall burden of stroke-related disability is large and increasing [1]. Despite the use of early thrombolysis and thrombectomy for ischaemic stroke, and organised stroke care, most patients fail to make a complete recovery after stroke. NeuroAid (MLC601), which originates from Traditional Chinese Medicine (TCM), was developed to enhance post-stroke recovery [2]. Studies have reported improvement in post-stroke disabilities after ischaemic stroke [3, 4], with the use of MLC601. Neuroaid II (MLC901) has recently been introduced. Non-clinical studies have confirmed its similarity in pharmacological profile with its precursor MLC601. Experiments demonstrated that the effect of MLC901 on neurite outgrowth and neuronal proliferation were comparable to that of MLC601. The neuroprotective effects as indicated by reduced LDH release, smaller infarct volume, and increased neuronal cell proliferation were also similar to MLC601 [5]. This case report aims to look into the benefits of MLC901 in post-haemorrhagic stroke-induced disabilities.

\section{Case Presentation}

Our patient, a 63-year-old male, right-handed, presented with a sudden onset of rightsided weakness and slurred speech. His past medical and surgical history include obstructive sleep apnoea, colon cancer, lymphoma, throat cancer, previous knee replacement surgery, and hypertension. On initial assessment, he was well, with left gaze preference, right neglect, dysphasia, right lower face weakness, right hemiplegia, and hemisensory loss. CT brain scan showed a left thalamic haemorrhage with intraventricular extension (Fig. 1). Over the next few days, he had fluctuating conscious levels, which was attributed to progressive hydrocephalus, and thus underwent ventriculoperitoneal shunt insertion. Following the shunt insertion, he became fully alert; however, his neurological status remained unchanged. He was prescribed anti-hypertensive medications and Neuroaid II two capsules three times a day immediately. Repeat CT brain showed reduction in the haemorrhage (Fig. 2).

He was transferred to a rehabilitation centre for intensive therapy. On the patient's second month review, clinical examination revealed sustained neurological deficits which included right lower field visual loss, right hemisensory loss, right cheek numbness, some hesitancy with words and right-sided lower facial and limb weakness (Medical Research Council MRC scale 3/5). At month 3, some improvements in his post-stroke deficits were noted such as return of pain sensation in his right cheek, better fluency with words, and reduced lower facial and limb weakness (MRC 4/5). At his sixth month follow-up, he was able to walk with a right hemiplegic gait with a stick. However, he continued to have deficits in terms of right lower visual field loss, mild right face and limb weakness, and right hemisensory loss. CT brain showed resolution of the haemorrhage, small hypodensity of the left thalamus to the corona radiata (Fig. 3).

\section{Discussion/Conclusion}

Over the years, the use of TCM and complementary and alternative medicine for stroke recovery has become more prevalent and widely accepted [6]. Neuroaid (MLC601), is one

\section{Karger'=}




\section{Case Reports in Neurology}

Case Rep Neurol 2020;12:212-217

DOI: $10.1159 / 000508588$

(c) 2020 The Author(s). Published by S. Karger AG, Basel www.karger.com/crn

Tan et al.: NeuroAid II (MLC901) in Haemorrhagic Stroke

such example of TCM, it combines 9 herbal (including Radix astragali, Radix salviae miltiorrhizae, Radix paeoniae rubra, Rhizoma chuanxiong, Radix angelicae sinensis, Carthamus tinctorius, Prunus persica, Radix polygalae, and Rhizoma acori tatarinowii) and 5 animal components (including Hirudo, Eupolyphaga seu steleophaga, Calculus bovisartifactus, Buthus martensii, and Cornu saigae tataricae). It was first registered by the Sino Food and Drug Administration in 2001 after initial clinical trials done in China reported that MLC601 has improved functional outcome and recovery from post-stroke disability [7]. Over the next few years, many studies have reported on the benefits of MLC601, including a double-blind, placebocontrolled pilot study to investigate the potential efficacy of MLC601 in enhancing post-stroke recovery, which indicated that some positive trends were observed in the MLC601 group, and thus it may be useful for post-stroke rehabilitation $[3,4,8,9]$. With regards to its safety profile, long-term laboratory data (biochemical, haematological, or electrocardiogram tests) confirms safety of MLC601 in acute stroke patients receiving a 3-month treatment, with no risk of increased haemorrhage [10,11]. Currently, Neuroaid II (MLC901), a simplified version of MLC601 which contains solely herbal components, has been made available.

The exact mechanism of action of MLC601/MLC901 is unknown; however, there have been multiple postulations. In a rodent model of focal ischemia, neuroprotective effects were observed and post-stroke functional deficits were drastically decreased. Neuroproliferative benefits in terms of cell proliferation and development of dense axonal and dendritic network were also reported. One postulated mechanism of neurogenesis properties of MLC601/MLC901 is the ability to stimulate the expression of BDNF, a growth factor that evoke neurite outgrowth and differentiation [12]. At the same time, it enhanced cognitive recovery by reducing hippocampal CA1 cell degeneration and Bax expression in the rodent model [12]. A possible mechanism of the neuroprotective effect of MLC901 is the activation of ATP-sensitive potassium channels to produce large hyperpolarization and prevent massive release of excitotoxic glutamate in ischemic cells [13].

There are few treatments that improve recovery after haemorrhagic stroke. Multi-disciplinary rehabilitation should be commenced as soon as possible [14]. There is no proven pharmacotherapy. In our patient, following the left thalamic haemorrhagic stroke, he was started on long-term MLC901 in addition to blood pressure control and intensive rehabilitation, and was followed-up monthly. Within a span of 6 months, there was significant improvement in his motor, sensory, and speech deficits. There were no adverse events, no increased bleeding. Our case study helps to support the post-stroke recovery benefits of MLC901 in a patient with haemorrhagic stroke.

In conclusion, given the ever-increasing morbidity rates and global burden of poor functional outcomes in post-stroke patients, the need for effective rehabilitative therapy for patients to regain independence is high. The post-stroke recovery benefits of MLC601 and MLC901, in terms of their neuroproliferative and neuroprotective effects in rodent cell models, as well as clinical observations of improvement of neurological deficits in multiple studies indicate the possibility of a useful rehabilitative treatment. The extent of an individual patient's motor recovery varies widely [15], which makes it hard to accurately quantify the efficacy of MLC601/901. In this aspect of efficacy, clinical trials need to be done in haemorrhagic stroke. This study is limited as it is only a single case report. But it aims to highlight the neurological improvements in a post-haemorrhagic stroke patient, and provides support for trials of MLC601/901 in haemorrhagic stroke.

\section{Karger'=}




\section{Case Reports in Neurology}

\begin{tabular}{l|l}
\hline Case Rep Neurol 2020;12:212-217 \\
\hline DOI: 10.1159/000508588 & $\begin{array}{l}\text { @ 2020 The Author(s). Published by S. Karger AG, Basel } \\
\text { www.karger.com/crn }\end{array}$ \\
\hline
\end{tabular}

Tan et al.: NeuroAid II (MLC901) in Haemorrhagic Stroke

\section{Statement of Ethics}

This research complies with the guidelines for human studies and was conducted ethically in accordance with the World Medical Association Declaration of Helsinki. The patient gave written informed consent to publish the case (including publication of images).

\section{Conflict of Interest Statement}

N. Venketasubramanian has received funding from the CHIMES Society to perform clinical trials on NeuroAid. The other authors have no conflicts of interest to declare.

\section{Funding Sources}

There are no funding sources to disclose.

\section{Author Contributions}

Chai-Hoon Nowel Tan - prepared the manuscript. David Choy - principle neurosurgeon managing the patient, reviewed the manuscript. Narayanaswamy Venketasubramanian - conceived the project, was the principal clinician for the patient, guided the first author, reviewed the manuscript.

\section{References}

1 Johnson CO, Nguyen M, Roth GA, Nichols E, Alam T, Abate D, et al.; GBD 2016 Stroke Collaborators. Global, regional, and national burden of stroke, 1990-2016: a systematic analysis for the Global Burden of Disease Study 2016. Lancet Neurol. 2019 May;18(5):439-58.

2 Siddiqui FJ, Venketasubramanian N, Chan ES, Chen C. Efficacy and safety of MLC601 (NeuroAiD®), a traditional Chinese medicine, in poststroke recovery: a systematic review. Cerebrovasc Dis. 2013;35(s1 Suppl 1):8-17.

3 Zaki NH, Akran MA, Hasan AH, Farah IA. Observing the outcome of using Neuroaid [MLC601] on a sample of Iraqi Stroke Patients. Iraqi JMS. 2012;10:255-9.

4 Venketasubramanian N, Young SH, Tay SS, Umapathi T, Lao AY, Gan HH, et al.; CHIMES-E Study Investigators. CHInese Medicine NeuroAiD Efficacy on Stroke Recovery - Extension Study (CHIMES-E): A Multicenter Study of Long-Term Efficacy. Cerebrovasc Dis. 2015;39(5-6):309-18.

5 Heurteaux C, Gandin C, Borsotto M, Widmann C, Brau F, Lhuillier M, et al. Neuroprotective and neuroproliferative activities of NeuroAid (MLC601, MLC901), a Chinese medicine, in vitro and in vivo. Neuropharmacology. 2010 Jun;58(7):987-1001.

6 Yeh ML, Chiu WL, Wang YJ, Lo C. An Investigation of the Use of Traditional Chinese Medicine and Complementary and Alternative Medicine in Stroke Patients. Holist Nurs Pract. 2017 Nov/Dec;31(6):400-7.

7 Chen C, Venketasubramanian N, Gan RN, Lambert C, Picard D, Chan BP, et al. Danqi Piantang Jiaonang (DJ), a traditional Chinese medicine, in poststroke recovery. Stroke. 2009 Mar;40(3):859-63.

8 Kong KH, Wee SK, Ng CY, Chua K, Chan KF, Venketasubramanian N, et al. A double-blind, placebo-controlled, randomized phase II pilot study to investigate the potential efficacy of the traditional chinese medicine Neuroaid (MLC 601) in enhancing recovery after stroke (TIERS). Cerebrovasc Dis. 2009;28(5):514-21.

9 Suwanwela NC, Chen CL, Lee CF, Young SH, Tay SS, Umapathi T, et al.; CHIMES-E Study Investigators. Effect of Combined Treatment with MLC601 (NeuroAiDTM) and Rehabilitation on Post-Stroke Recovery: the CHIMES and CHIMES-E Studies. Cerebrovasc Dis. 2018;46(1-2):82-8.

\section{Karger'=}




\section{Case Reports in Neurology}

\begin{tabular}{l|l}
\hline Case Rep Neurol 2020;12:212-217 \\
\hline DOI: 10.1159/000508588 & $\begin{array}{l}\text { ○ 2020 The Author(s). Published by S. Karger AG, Basel } \\
\text { www.karger.com/crn }\end{array}$ \\
\hline
\end{tabular}

Tan et al.: NeuroAid II (MLC901) in Haemorrhagic Stroke

10 Young SH, Zhao Y, Koh A, Singh R, Chan BP, Chang HM, et al.; CHIMES Investigators. Safety profile of MLC601 (Neuroaid) in acute ischemic stroke patients: A Singaporean substudy of the Chinese medicine neuroaid efficacy on stroke recovery study. Cerebrovasc Dis. 2010;30(1):1-6.

11 Bavarsad Shahripour R, Hemati A, Hosseinzadeh Maleki A. A randomized trial to assess the long-term safety of NeuroAiD among Caucasian patients with acute ischemic stroke. Chin J Integr Med. 2014 Nov;20(11): 812-7.

12 Heurteaux C, Widmann C, Moha ou Maati H, Quintard H, Gandin C, Borsotto M, et al. NeuroAiD: properties for neuroprotection and neurorepair. Cerebrovasc Dis. 2013;35(Suppl 1):1-7.

13 Moha Ou Maati H, Borsotto M, Chatelain F, Widmann C, Lazdunski M, Heurteaux C. Activation of ATPsensitive potassium channels as an element of the neuroprotective effects of the Traditional Chinese Medicine MLC901 against oxygen glucose deprivation. Neuropharmacology. 2012 Sep;63(4):692-700.

14 Hemphill JC 3rd, Greenberg SM, Anderson CS, Becker K, Bendok BR, Cushman M, et al.; American Heart Association Stroke Council; Council on Cardiovascular and Stroke Nursing; Council on Clinical Cardiology. Guidelines for the Management of Spontaneous Intracerebral Hemorrhage: A Guideline for Healthcare Professionals From the American Heart Association/American Stroke Association. Stroke. 2015 Jul;46(7):2032-60.

15 Stinear CM. Prediction of motor recovery after stroke: advances in biomarkers. Lancet Neurol. 2017 Oct;16(10):826-36.

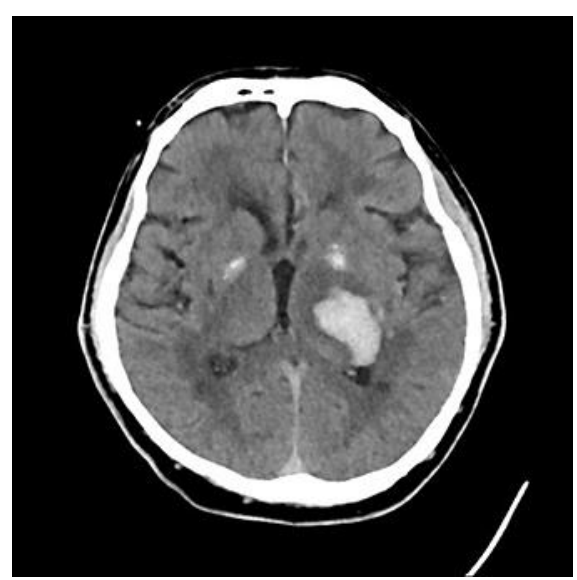

Fig. 1. CT brain showing left thalamic haemorrhagic stroke with intraventricular extension. 
Case Reports in Neurology
Case Rep Neurol 2020;12:212-217

DOI: 10.1159/000508588

(c) www.karger.com/crn

Tan et al.: NeuroAid II (MLC901) in Haemorrhagic Stroke

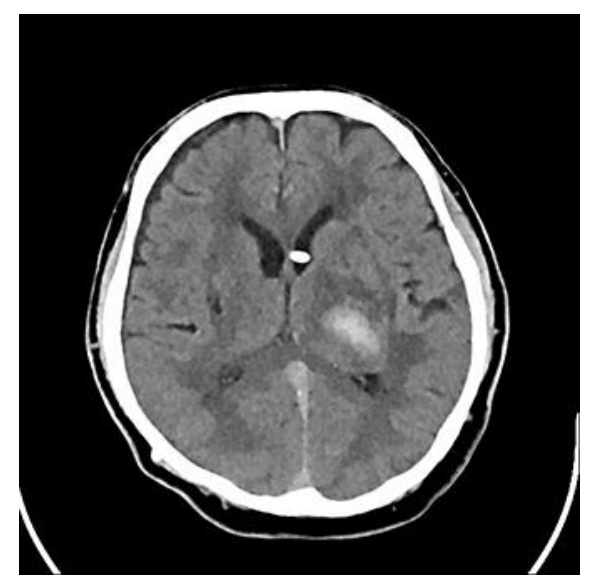

Fig. 2. CT brain a week later showing reduction in the thalamic haemorrhage.

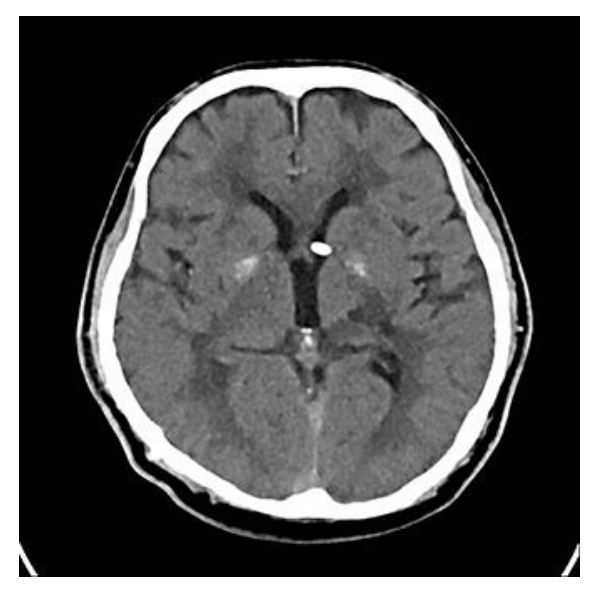

Fig. 3. CT brain at month 6 showing resolution of the thalamic haemorrhage.

\section{Karger'}

